\title{
The Adsorption of Sulfur by Microporous Materials
}

\author{
M. STEIJNS AND P. MARS \\ Twente Universily of Technology, Department of Chemical Engineering, P. O. Box 217, \\ Enschede, The Netherlands
}

Received November 13, 1975; accepted February 2, 1976

\begin{abstract}
The sorption of sulfur by the zeolites $\mathrm{NaX}(=13 X)$ and $\mathrm{Ca} A(=5 A)$ and an activated charcoal prepared from sugar was investigated at temperatures between 150 and $350^{\circ} \mathrm{C}$ and relative sulfur pressures between $10^{-4}$ and $10^{-1}$. The adsorbate-adsorbate interaction indicated by the $S$-shaped isotherm for the zeolite $\mathrm{NaX}$ points to physical or chemical interaction of sulfur molecules in neighboring supercages. In $\mathrm{Ca} A$ adsorbate-adsorbate interaction between sulfur species in different supercages is negligible. Below $200^{\circ} \mathrm{C}$ the rate of sulfur uptake by the zeolite $\mathrm{Ca} A$ is determined by the diffusion rate of a sulfur species through the zeolitic framework. In activated charcoal a strong adsorbateadsorbent interaction is present and part of the sulfur is chemisorbed at $350^{\circ} \mathrm{C}$. The differences in the density of the adsorbed sulfur determined with three different methods indicate that even at full saturation of the micropore volume with sulfur, there is still some residual adsorption volume.
\end{abstract}

\section{INTRODUCTION}

Porous materials containing sorbed sulfur can be used as catalysts or adsorbents for special applications. Incorporation of sulfur $(4 \mathrm{wt} \%)$ in a $\mathrm{Na} X(=13 X)$ aluminosilicate zeolite raises the catalytic activity for $n$-hexane cracking by a factor five to ten (1). Dudzik and Preston (2) report a correlation between the amount of sulfur radicals in zeolite $\mathrm{K} A$ $(=3 A)$ and the catalytic activity for the cracking of 2,3-dimethylbutane. We found that the selective oxidation of $\mathrm{H}_{2} \mathrm{~S}$ by oxygen to sulfur is catalyzed by sulfur adsorbed in zeolites or active carbon, so that an autocatalytic reaction occurs (3).

Sulfur impregnated active carbons may be used as an adsorbent for the removal of mercury traces from gas streams (4). The slow desorption rate of sulfur trapped in microporous materials makes these materials convenient as fumigant (5). One may suggest that preadsorption of sulfur in a material may create an adsorbent with a lower affinity towards polar adsorbates.

In the last decade the sorption of sulfur by zeolites has been the subject of several studies $(2,5,6)$. The sorption of sulfur by the zeolites $\mathrm{Ca} A(=5 A)$ and $\mathrm{NaX}(=13 X)$ has been studied by Barrer and Whiteman (5). They found that the sorption of sulfur by these zeolites was fully reversible despite the high affinity between the aluminosilicate and the sulfur. Seff (6) determined the nature of a sulfur sorption complex in zeolite $\mathrm{Na} A(=4 A)$ by single crystal $\mathrm{X}$-ray technique. Two $\mathrm{S}_{8}$ rings in the crown configuration lie parallel to each other in the large cavity of each unit cell.

Regarding the sorption of sulfur vapor by various carbons, a review of the studies up to 1950 is given by Gmelin (7). Wibaut and van der Kam (8) reported that a part of the sulfur is chemisorbed at the carbon surface, especially at temperatures above $400^{\circ} \mathrm{C}$. This sulfur desorbs as $\mathrm{CS}_{2}$ and $\mathrm{H}_{2} \mathrm{~S}$ when the active carbon is heated in nitrogen up to $1000^{\circ} \mathrm{C}$. Recently Puri and Hazra (9) studied the chemical fixation of sulfur by active carbon and they corroborate the results of Wibaut and van der Kam (8).

The aim of this paper is a comparison of the 


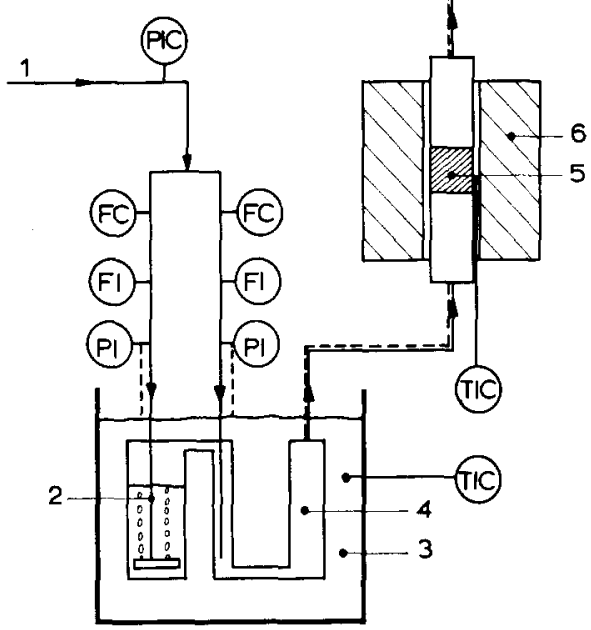

Fic. 1. Sulfur adsorption apparatus. 1: nitrogen; 2: liquid sulfur; 3 : silicone oil; 4 : mixing compartment; 5: porous material; 6: furnace; 7 : condensor (glass beads). ( $\because$ ) heated line.

sulfur adsorption in some zeolites and active carbons. The density of the sorbed sulfur is determined by different techniques. The structure of the adsorbed sulfur will be discussed. In the next paper (10) a study of the mercury chemisorption by sulfur containing porous materials is described.

\section{MATERIALS AND METHODS}

\section{Materials}

The active carbon was prepared by steam activation of pyrolysed sugar. The molecular sieve zeolites $\mathrm{NaX}$ and $\mathrm{Ca} A$ were commercial products obtained from the Linde Division of Union Carbide. Before use pellets of the zeolite were pressed from the available powder (0.5-5 $\mu \mathrm{m})$. These pellets were grinded and the sieve fraction $0.3-0.6 \mathrm{~mm}$ was used in the experiments.

\section{Sulfur Adsorption}

The sulfur adsorption of porous materials was measured in the apparatus depicted in
Fig. 1. A nitrogen stream was saturated with sulfur at temperatures ranging from $140-160^{\circ} \mathrm{C}$. By admixing nitrogen to this stream, the relative pressure of sulfur at the adsorbent outer surface could be varied between $10^{-4}$ and $10^{-1}$. The relative pressure of sulfur was calculated at the adsorbent temperature using thermodynamic data for the equilibria in sulfur vapor given by Lepsoe (11). Although Lepsoe considers only $S_{2}, S_{6}$, and $S_{8}$, minor difference occur when also $S_{3}, S_{4}, S_{5}$, and $S_{7}$ are included in the calculations (12). At $325^{\circ} \mathrm{C}$ and a relative sulfur pressure of $10^{-4} \mathrm{~S}_{2}$ turns out to be the predominant species in the sulfur vapor. At the same temperature but a relative pressure of $10^{-2} \mathrm{~S}_{6}$ is the main sulfur species in the vapor.

A continuous flow of the nitrogen-sulfur mixture was led through a bed of about $1 \mathrm{~g}$ adsorbent. The uptake of sulfur by the material was followed gravimetrically. The rate of sulfur sorption by the materials is fast and a breakthrough of sulfur occurs when the adsorption equilibrium is almost established (>90\%). The sulfur which did not adsorb was collected in a condensor. The amount of evaporated sulfur was calculated in each experiment and was always within $15 \%$ of the sum of the sulfur weights in the adsorber and in the condensor.

\section{Determination of the Apparent Density of Adsorbed Sulfur}

Three methods were used for the determination of the sulfur density:

Method 1. From the maximum uptake of sulfur in the known micropore volume of a material an apparent density could be calculated. The micropore volume of $\mathrm{NaX}$ and $\mathrm{CaA}$ is identical with the volume of the supercages and connecting channels. This volume may be derived from the structure of the zeolites determined with X-ray techniques. According to Breck (13) the limiting adsorption volume is $0.296 \mathrm{~cm}^{3} \cdot \mathrm{g}^{-1}$ for $\mathrm{NaX}$ and $0.27 \mathrm{~cm}^{3} \cdot \mathrm{g}^{-1}$ for $\mathrm{Ca} A$. For the micropore volume of activated sugar charcoal we will use the constant $W_{0}$ in 


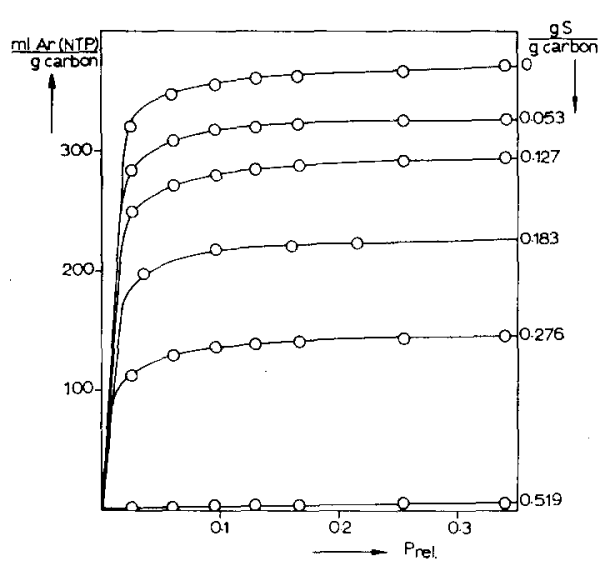

FIG. 2. Adsorption isotherms of argon at $-196^{\circ} \mathrm{C}$ on active carbon with variable sulfur load.

the first Dubinin equation (14). From the benzene adsorption isotherm we derived a value of $0.448 \mathrm{~cm}^{3} \cdot \mathrm{g}^{-1}$ for this charcoal.

Method 2. From the apparent volume of a sulfur containing material in methanol, which increases upon sulfur deposition, it is possible to calculate the density of adsorbed sulfur at $20^{\circ} \mathrm{C}$.

Method 3. From the argon isotherms of materials with variable sulfur load the apparent density of sulfur at $-196^{\circ} \mathrm{C}$ was determined. As an example argon isotherms are shown for some sulfurized sugar charcoals in Fig. 2. From the amount of adsorbed argon at a relative argon pressure of 0.25 we calculated a micropore volume accessible to argon at $-196^{\circ} \mathrm{C}$. From the amount of sorbed argon in $\mathrm{NaX}$ at $P_{\text {rel }}=0.25$ and the known micro- pore volume we calculated a density of 1.22 $\mathrm{g} \cdot \mathrm{cm}^{-3}$ for the adsorbed argon. According to literature (15) the density of adsorbed argon at $-196^{\circ} \mathrm{C}$ is closer to the value for supercooled bulk liquid $\left(1.47 \mathrm{~g} \mathrm{~cm}^{-3}\right)$ than the value for solid argon $\left(1.62 \mathrm{~g} \mathrm{~cm}^{-3}\right)$. The value of 1.22 $\mathrm{g} \mathrm{cm}^{-3}$ for adsorbed argon in $\mathrm{NaX}$ is probably due to a limited attachment to the pore-walls.

The adsorption of argon in $\mathrm{Ca} A$ proceeds so slowly that we could not determine the isotherm. The density of adsorbed argon in activated charcoal was $1.46 \mathrm{~g} \mathrm{~cm}^{-3}$, which is very close to the density of supercooled argon at $-196^{\circ} \mathrm{C}$, i.e., $1.47 \mathrm{~g} \mathrm{~cm}^{-3}$.

\section{RESULTS AND DISCUSSION}

\section{Adsorption Isotherms of Sulfur on $\mathrm{NaX}$, CaA, and Activated Sugar Charcoal}

The first parts of the isotherms are given in the Figs. 3-5. For all our materials already more than $90 \%$ of the maximum sulfur uptake is reached at a relative pressure of $10^{-2}$. (Table I). This is characteristic for adsorption in micropores.

The isotherm of $\mathrm{NaX}$ (Fig. 3) is slightly S-shaped, which points to an adsorbateadsorbate interaction. The isotherm of $\mathrm{CaA}$ (Fig. 4) does, however, not show this typical shape. Barrer and Whiteman (5), who also investigated the sorption of sulfur in $\mathrm{NaX}$, did not observe this phenomenon. This because they performed no experiment at low relative pressures $\left(10^{-4}-5 \cdot 10^{-3}\right)$. For the sorp-

\section{TABLE I}

Ratio between the Density of adsorbed Sulfur at full Saturation of the Micropore Volume with Sulfur and the Density of the Bulk Liquid Sulfur at Adsorption Temperature

\begin{tabular}{ccllccc}
\hline Materials & Temperature & $P_{\text {rol }}$ & $\mathrm{gS}(\mathrm{g})^{-1}$ & $\rho_{\text {ad }}\left(\mathrm{g} / \mathrm{cm}^{3}\right)$ & $\rho \mathrm{s}\left(\mathrm{g} / \mathrm{cm}^{3}\right)$ & $\rho_{\text {ad }} / \rho \mathrm{s}$ \\
\hline $\mathrm{Na} X$ & 200 & 0.09 & 0.307 & 1.03 & 1.75 & 0.591 \\
$\mathrm{Na} X$ & 260 & 0.009 & 0.300 & 1.01 & 1.72 & 0.588 \\
$\mathrm{Na} X$ & 290 & 0.004 & 0.284 & 0.95 & 1.70 & 0.561 \\
$\mathrm{Ca} A$ & 200 & 0.09 & 0.225 & 0.83 & 1.75 & 0.474 \\
$\mathrm{Ca} A$ & 250 & 0.01 & 0.230 & 0.85 & 1.73 & 0.493 \\
$\mathrm{Ca} A$ & 300 & 0.005 & 0.229 & 0.85 & 1.70 & 0.500 \\
$\mathrm{Carbon}$ & 180 & 0.24 & 0.693 & 1.55 & 1.77 & 0.873 \\
Carbon & 190 & 0.128 & 0.679 & 1.53 & 1.76 & 0.867 \\
\hline
\end{tabular}




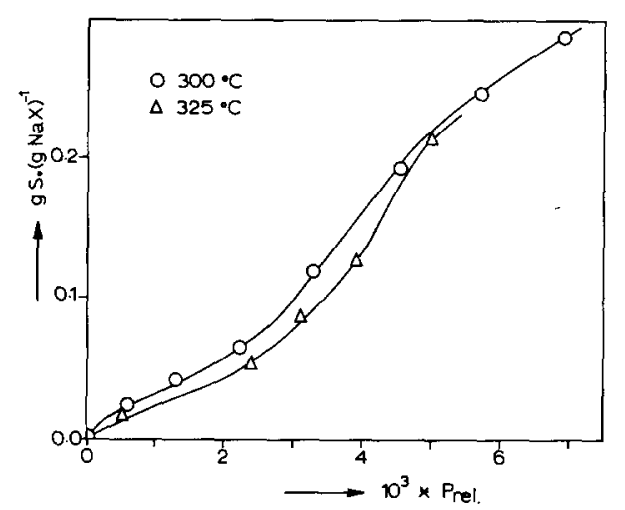

Fig. 3. Adsorption isotherms of sulfur on NaX Zeolite at 300 and $325^{\circ} \mathrm{C}$.

tion of phosphorus in $\mathrm{NaX}$ they found isotherms in the relative pressure range $10^{-4}-10^{-2}$ similar to ours.

The interaction between sorbed sulfur molecules may be physical or chemical. In the latter case an association to larger chains and rings takes place. Adsorbate-adsorbate interaction between sorbed sulfur species within one supercage is equal for $\mathrm{Ca} A$ and $\mathrm{NaX}$, because the volumes of the supercages are almost equal, i.e., $\mathrm{Ca} A$ : $775 \AA^{3}$ and $\mathrm{NaX}$ : $822 \AA^{3}$ (13).

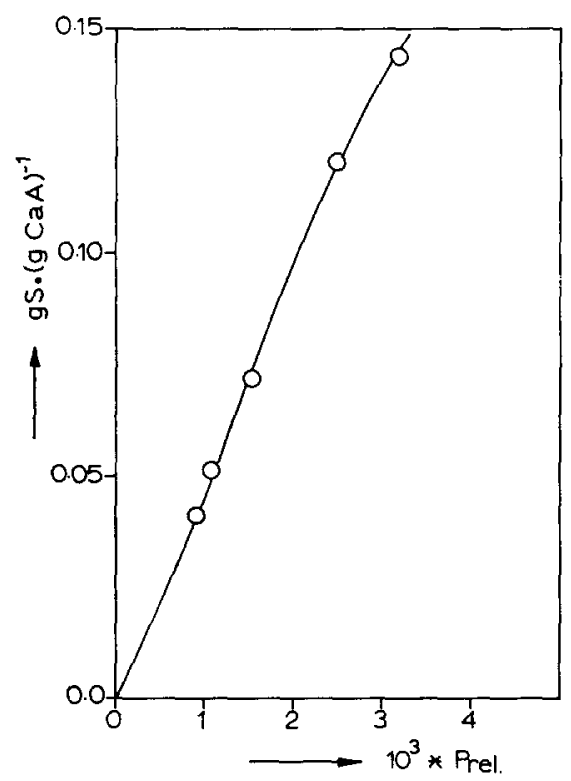

Fig. 4. Adsorption isotherms of sulfur on $\mathrm{Ca} A$ zeolite at $330^{\circ} \mathrm{C}$.

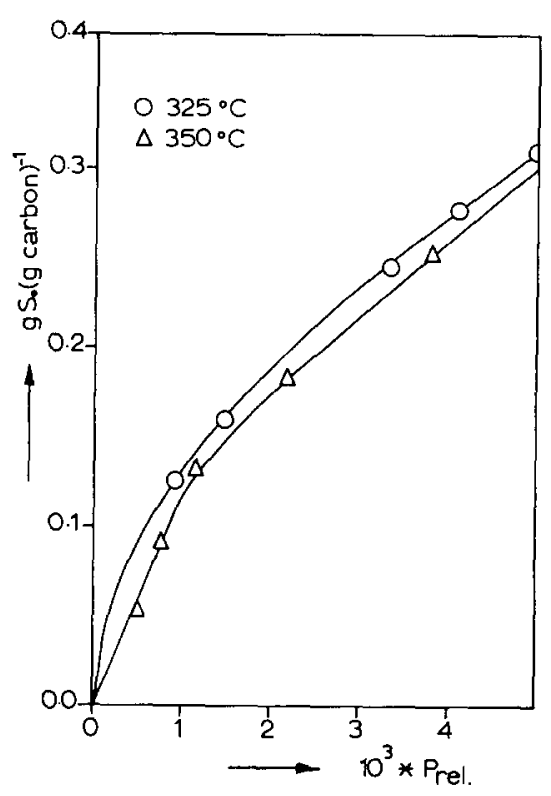

FIG. 5. Adsorption isotherms of sulfur on activated sugar charcoal at 325 and $350^{\circ} \mathrm{C}$.

Therefore the differences in adsorption isotherms on $\mathrm{Ca} A$ and $\mathrm{NaX}$ lead to the conclusion that the adsorbed sulfur forms an interconnecting net in the supercages and channels of the zeolite $\mathrm{NaX}$. Because of the small apertures in $\mathrm{Ca} A(4.3 \AA)$ there is no physical or chemical interaction between sulfur species in neighboring supercages.

In active carbon the rather strong interaction between adsorbed sulfur and the carbon surface, explains that an adsorbate-adsorbate interaction does not determine the shape of the isotherm (Fig. 5).

Adsorbate-adsorbate interaction leads to S-shaped isotherms in the case of water on activated charcoal (16) and xenon in $\mathrm{NaX}$ and $\mathrm{LiX}$ zeolites (17). In the case of water on charcoal the inflection point lies at a relative pressure of 0.4 and this isotherm is therefore an example of type $\mathrm{V}$ isotherms in Brunauer's classification (18). For xenon in $\mathrm{NaX}$ and $\mathrm{Li} X$ the inflection point lies in the relative pressure range $10^{-4}-10^{-2}$, which is also observed for sulfur and phosphorus in $\mathrm{NaX}$. These isotherms have features of type $\mathrm{I}$ and type $\mathrm{V}$ isotherms, because it concerns adsorb- 
TABLE II

Apparent Density of the Adsorbed Sulfur

\begin{tabular}{|c|c|c|c|c|c|c|}
\hline Material & gS (g material) $)^{-1}$ & $T_{\mathrm{ad} x}$ & Methoda & $\rho_{\mathrm{ad}}\left(\mathrm{g} / \mathrm{cm}^{3}\right)$ & $\rho 8\left(\mathrm{~g} / \mathrm{cm}^{3}\right)$ & $\rho_{\mathrm{sd}} / \rho \mathrm{s}$ \\
\hline $\mathrm{Na} X$ & 0.1 & 325 & 3 & 0.92 & 2.12 & 0.43 \\
\hline $\mathrm{NaX}$ & 0.1 & 325 & 2 & 2.1 & 2.05 & 1.0 \\
\hline $\mathrm{Na} X$ & 0.3 & 200 & 3 & 1.0 & 2.12 & 0.47 \\
\hline $\operatorname{Na} X$ & 0.3 & 200 & 2 & 1.9 & 2.05 & 0.93 \\
\hline $\operatorname{NaX}$ & 0.3 & 200 & 1 & 1.0 & 1.75 & 0.57 \\
\hline $\mathrm{Ca} A$ & 0.1 & 325 & 2 & 1.8 & 2.05 & 0.88 \\
\hline $\mathrm{Ca} A$ & 0.23 & 225 & 2 & 1.8 & 2.05 & 0.88 \\
\hline $\mathrm{Ca} A$ & 0.23 & 225 & 1 & 0.85 & 1.74 & 0.49 \\
\hline Carbon & 0.25 & 350 & 3 & 1.1 & 2.12 & 0.52 \\
\hline Carbon & 0.25 & 350 & 2 & 1.6 & 2.05 & 0.78 \\
\hline Carbon & 0.50 & 300 & 3 & 1.2 & 2.12 & 0.57 \\
\hline Carbon & 0.50 & 300 & 2 & 1.7 & 2.05 & 0.83 \\
\hline Carbon & 0.69 & 180 & 3 & 1.6 & 2.12 & 0.76 \\
\hline Carbon & 0.69 & 180 & 1 & 1.6 & 1.77 & 0.90 \\
\hline
\end{tabular}

a 1 = maximum sulfur uptake; density of sulfur at adsorption temperature; 2 = methanol; density of sulfur at $20^{\circ} \mathrm{C} ; 3=$ argon; density of sulfur at $-196^{\circ} \mathrm{C}$.

ate-adsorbate interactions during the filling of micropores.

Below $200^{\circ} \mathrm{C}$ the sorption of sulfur by $\mathrm{Ca} A$ is a slow process. The diffusion rate of a sulfur species through the zeolite framework determines the sorption rate of sulfur. In zeolite $\mathrm{KA}(=3 \mathrm{~A})$ the sorption of sulfur starts at $350^{\circ} \mathrm{C}$ according to literature (2). The diameter of the apertures in $\mathrm{K} A$ is $3.3 \AA$, compared to a cross-sectional diameter of $3.7 \AA$ for $S_{2}$, which is probably the diffusing species. Barrer and Whiteman (5) present evidence that the sulfur diffuses as chain molecules instead of $\mathrm{S}_{2}$ molecules through the channels and cages of $\mathrm{CaA}$. The main species in the sulfur vapor at $200^{\circ} \mathrm{C} \mathrm{S} 8$ (diameter $8.5 \AA$ ) is certainly not the diffusing species in $\mathrm{CaA}$ (window diameter ca. $4.3 \AA$ ). From our observations it is not possible to discriminate between chains and $\mathrm{S}_{2}$ molecules.

Sulfur is sorbed copiously by activated sugar charcoal. Only a small part, about $0.05 \mathrm{~g}$ sulfur per $\mathrm{g}$ carbon, is chemisorbed at $350^{\circ} \mathrm{C}$. In the Introduction we mentioned that other authors $(8,9)$ also found this chemisorption of sulfur by active carbon.

Some experiments were performed on sulfur adsorption in porous alumina, porous silica, and carbon black. In all cases at relative sulfur pressures below 0.1 sulfur adsorption is negligible $\left.(<0.01 \mathrm{~g} \text { ( } \mathrm{g} \text { material })^{-1}\right)$. This will be caused by the absence of pores of molecular diameter in these cases.

\section{The Apparent Density of the Adsorbed Sulfur in $N a X, C a A$, and Activated Sugar charcoal}

We used three different methods for the determination of the density of the adsorbed sulfur as discussed in the Section entitled Materials and Methods.

The results obtained with method 1 are summarized in Table I. The ratio of the densities of adsorbed $\left(\rho_{\mathrm{ad}}\right)$ and bulk liquid sulfur $\left(\rho_{\mathrm{S}}\right)$ at the adsorption temperature is given for the microporous materials at full saturation with sulfur. In all cases this ratio is below unity, which may be expected for the accommodation of $S_{8}$ rings or/and $S_{x}$-chains in cages and pores of molecular diameter. Remarkable is that Barrer and Whiteman (5) report ratios for $\mathrm{NaX}$ and $\mathrm{Ca} A$ which are about $40 \%$ higher than our values. We have no reasonable 
explanation for this difference. In case of active carbon the density of adsorbed sulfur differs not so much from that of liquid sulfur. This must be due to the strong adsorbateadsorbent interaction and/or by the larger mean pore radius. The apparent density of sulfur in $\mathrm{NaX}$ is about $20 \%$ higher than in $\mathrm{Ca} A$ which reflects the stronger interaction between adsorbed sulfur species in $\mathrm{NaX}$ as discussed in the preceding paragraph.

In Table II a survey is given of the sulfur densities as a function of the sulfur content of the materials. The densities were determined with three different methods. The ratio between the apparent density of adsorbed sulfur and the density of elemental sulfur at a corresponding temperature is given. For method 1 this temperature is the adsorption temperature, for method 2 (methanol) this is $20^{\circ} \mathrm{C}$ and for method 3 (argon) it is $-196^{\circ} \mathrm{C}$.

The densities measured with methanol are always higher than those calculated from the saturation value or the argon isotherm. The low apparent density of adsorbed sulfur points to a residual micropore volume which is not accessible to argon at $-196^{\circ} \mathrm{C}$ or sulfur species at $200-300^{\circ} \mathrm{C}$ but methanol at room temperature may partly fill this space. Walker and Sinha (19) observed a similar effect upon sulfur adsorption in Saran active carbon. The adsorption of carbon dioxide at $25^{\circ} \mathrm{C}$ is observed by these authors, but nitrogen does not adsorb at $-196^{\circ} \mathrm{C}$. Our conclusion is that deposition of sulfur leads to a pore-narrowing and/or formation of bottle-necks which prevent passage of large molecules especially at low temperatures. Puri and Hazra (9) who also observed this effect for active carbons, launched the idea that in this way it is possible to prepare carbon molecular sieves.

In the next paper we will introduce the chemisorption of mercury as a method to study the structure of the adsorbate and/or adsorbent.

\section{ACKNOWLEDGMENT}

We thank A. Peppelenbos and G. J. Hageman for carrying out part of the experimental work. The sugar charcoal was activated by Norit Laboratories in Amersfoort, The Netherlands. The investigations were supported by the organization for chemical research in the Netherlands (SON) with financial aid of the organization for pure research (ZWO).

\section{REFERENCES}

1. Miate, J. N. ANd Weisz, P. B., J. Catal. 20, 288 (1971).

2. Dudzik, Z. And Preston, K., J. Colloid Interface Sci. 26, 374 (1968).

3. Steijns, M. And Mars, P., J. Catal. 35, 11 (1974).

4. Lovett, W. D. And Cunniff, F. T., Chem. Eng. Prog. 70, (5) 43 (1974).

[5. Barrer, R. M. and Whiteman, J. L., J. Chem. Soc. A 13, (1967).

6. SEFF, K., J. Phys. Chem. 76, 2601 (1972).

7. Gmelins Handbuch der Anorganischen Chemie 9, (A3) 617 (1953).

8. Wibaut, J. P. And Van der Kam, E. J., Rec. Trav. Chim. Pays Bas 49, 121 (1930).

9. Puri, B. R., and Hazra, R. S., Carbon 9, 123 (1971).

10. Steijns, M., Peppelenbos, A., and Mars, P., J. Colloid Interface Sci. 56, (1976).

11. Lepsoe, R., Ind. Eng. Chem. 30, 92 (1938).

12. Detry, D., Drowart, J., Goldfinger, P., Keller, H., And Rickert, H., Z. Phys. Chem. (Frankf.) 55,314 (1967).

13. BRECK, D. W., "Zeolite Molecular Sieves," WileyInterscience, New York, 1974.

14. Dubinin, M. M., Chem. Rev. 60, 235 (1960).

15. Holmes, H. F., Fuller, E. L. JR., AND BeH, R. A., J. Colloid Interface Sci. 47, 365 (1974).

16. Coolmge, A. S., J. Amer. Chem. Soc. 49, 708 (1928).

17. Kiselev, A. V., Aristov, B. G., AND Bosacek, V., Trans. Faraday Soc. 63, 2057 (1967).

18. Brunauer, S., Deming, L. S., Deming, W. E., and Teller E., $J$. Amer. Chem. Soc. 62, 1723 (1940),

19. Sinha, R. K., AND Walker, P. L. JR., Carbon 10, 754 (1972). 